\title{
In vitro antifungal activity of hydroxychavicol isolated from Piper betle $\mathrm{L}$
}

\author{
Intzar Ali ${ }^{1}$, Farrah G Khan ${ }^{3}$, Krishan A Suri ${ }^{2}$, Bishan D Gupta ${ }^{2}$, Naresh K Satti ${ }^{2}$, Prabhu Dutt ${ }^{2}$, Farhat Afrin ${ }^{4}$,
} Ghulam N Qazi ${ }^{4}$, Inshad A Khan ${ }^{1 *}$

\begin{abstract}
Background: Hydroxychavicol, isolated from the chloroform extraction of the aqueous leaf extract of Piper betle L., (Piperaceae) was investigated for its antifungal activity against 124 strains of selected fungi. The leaves of this plant have been long in use tropical countries for the preparation of traditional herbal remedies.

Methods: The minimum inhibitory concentration (MIC) and minimum fungicidal concentration (MFC) of hydroxychavicol were determined by using broth microdilution method following CLSI guidelines. Time kill curve studies, post-antifungal effects and mutation prevention concentrations were determined against Candida species and Aspergillus species "respectively". Hydroxychavicol was also tested for its potential to inhibit and reduce the formation of Candida albicans biofilms. The membrane permeability was measured by the uptake of propidium iodide.
\end{abstract}

Results: Hydroxychavicol exhibited inhibitory effect on fungal species of clinical significance, with the MICs ranging from 15.62 to $500 \mu \mathrm{g} / \mathrm{ml}$ for yeasts, 125 to $500 \mu \mathrm{g} / \mathrm{ml}$ for Aspergillus species, and 7.81 to $62.5 \mu \mathrm{g} / \mathrm{ml}$ for dermatophytes where as the MFCs were found to be similar or two fold greater than the MICs. There was concentration-dependent killing of Candida albicans and Candida glabrata up to $8 \times$ MIC. Hydroxychavicol also exhibited an extended post antifungal effect of 6.25 to $8.70 \mathrm{~h}$ at $4 \times$ MIC for Candida species and suppressed the emergence of mutants of the fungal species tested at $2 \times$ to $8 \times$ MIC concentration. Furthermore, it also inhibited the growth of biofilm generated by C. albicans and reduced the preformed biofilms. There was increased uptake of propidium iodide by $C$. albicans cells when exposed to hydroxychavicol thus indicating that the membrane disruption could be the probable mode of action of hydroxychavicol.

Conclusions: The antifungal activity exhibited by this compound warrants its use as an antifungal agent particularly for treating topical infections, as well as gargle mouthwash against oral Candida infections.

\section{Background}

Mycosis constitutes a common health problem, especially in tropical and subtropical developing countries; dermatophytes, Malassezia species and Candida species being the most frequent pathogens in humans and animals [1]. In recent years, there has been an increasing search for new antifungal agents. However, since many of the available antifungal drugs have undesirable side effects or are very toxic (amphotericin B), produce recurrence, show drug-drug interactions (azoles) or lead to the development of resistance (fluconazole, 5-

\footnotetext{
* Correspondence: iakhan@iiim.res.in

${ }^{1}$ Clinical Microbiology Division Indian Institute of Integrative Medicine, Canal Road, Jammu-180 001, India
}

flucytosine), some shows ineffectiveness [2,3] and have become therefore less successful in therapeutic strategies. Therefore it is necessary to search for more effective and less toxic novel antifungal agents that would overcome these disadvantages. Interestingly, plants are widely employed in folk medicine, mainly in communities with inadequate conditions of public health and sanitation. Several medicinal plants have been extensively studied in order to find more effective and less toxic compounds [4].

Piper betle L., (Piperaceae) has been extensively used in traditional herbal remedies in India, China, Taiwan, Thailand and many other countries. It is reported for various pharmacological activities such as antimicrobial, antioxidant, antimutagenic, anticarcinogenic, 
antiinflammatory [5] etc. It also acts as a stimulant, a breath freshener, a carminative, a sialagogue, a cardiac tonic, a pain killer in joint pain, an aphrodisiac, an astringent, an antiseptic [5-7], a digestive and pancreatic lipase stimulant [8], wound healing [9].

Hydroxychavicol is the major phenolic component, isolated from the aqueous extract of $P$. betle L., leaf has been reported to possess antinitrosation, antimutagenic, anticarcinogenic activities [10]. It also has a tendency to act as an antioxidant, and a chemopreventive agent [10]. Other useful properties include antiinflammatory, antiplatelet and antithrombotic without impairing haemostatic functions [11]. There have been reports on the antibacterial activities of hydroxychavicol $[12,13]$, but so far the report on its antifungal activity is lacking.

The present study was sought to investigate the effects of hydroxychavicol on fungal pathogens. In addition its effect on membrane permeability of C. albicans was also examined.

\section{Methods}

\section{Antifungal agents}

Hydroxychavicol (Fig. 1) was isolated in the pure form from the chloroform extraction of the aqueous leaf extract of $P$. betle L., (Piperaceae) as described previously [12]. Amphotericin B was purchased from Sigma Chemical Co. (St. Louis, MO), and terbinafine was obtained as kind gift from Lupin Laboratories, Pune, India.

\section{Fluorochrome dye}

Propidium iodide (Sigma), a small cationic, nucleic acidbinding fluorochrome largely excluded by intact cell membranes was used to stain the yeast cells [14]. Sodium deoxycholate (Sigma), an anionic detergent, was



used to facilitate diffusion of propidium iodide into the yeast cell membranes which were damaged by the antifungal agent [15].

\section{Fungal strains and growth conditions}

A total of 124 fungal strains were tested for their susceptibility to hydroxychavicol. These strains comprised of Candida albicans (ATCC 90028, ATCC 10231 and 23 clinical isolates), Candida glabrata (ATCC 90030 and 7 clinical isolates), Candida krusei (ATCC 6258 and 3 clinical isolates), Candida parapsilosis (ATCC 22019 and 5 clinical isolates), Candida tropicalis (ATCC 750 and 11 clinical isolates), Cryptococcus neoformans (ATCC 204092 and 2 clinical isolates), Aspergillus flavus (MTCC 1973, MTCC 2799 and 10 clinical isolates), Aspergillus fumigatus (MTCC 1811 and 17 clinical isolates), Aspergillus niger (ATCC 16404 and 6 clinical isolates), Aspergillus parasiticus (MTCC 2796), Epidermophyton floccosum (MTCC 613 and 1 clinical isolate), Microsporum canis (MTCC 2820 and 3 clinical isolates), Microsporum gypsium (MTCC 2819 and 2 clinical isolates), Trichophyton mentagrophytes (ATCC 9533 and 7 clinical isolates), and Trichophyton rubrum (MTCC 296 and 9 clinical isolates). Reference strains were procured from the American Type Culture Collection (ATCC, Manassas, VA, USA), and Microbial Type Culture Collection (MTCC, Chandigarh, India). The clinical isolates were obtained from the Department of Microbiology, Acharya Shri Chander College of Medical Sciences, Sidhra, Jammu, India.

\section{"Inoculum" preparation}

Suspensions of the yeasts and Aspergillus species were prepared in sterile normal saline $(0.85 \%)$ containing $0.05 \%$ polysorbate 20 (NST) from $24 \mathrm{~h}$ (48 h for C. neoformans) and 7-day-old cultures "respectively" grown on potato dextrose agar (Difco Laboratories, Detroit, Mich) at $35^{\circ} \mathrm{C}[16,17]$. A stock inoculums suspension of each dermatophytes was prepared from fresh, mature (7-dayold) cultures grown on potato dextrose agar with $2 \%$ inhouse rice flour slants at $28^{\circ} \mathrm{C}$. The densities of these suspensions were adjusted with a spectrophotometer (Multiskan spectrum, Thermo electron, Vantaa, Finland) at a wavelength of $530 \mathrm{~nm}$ to a transmittance of 65 to $70 \%$ to yield an initial inoculum of $1 \times 10^{6}$ to $5 \times 10^{6}$ $\mathrm{cfu} / \mathrm{ml}$ [18]. All adjusted suspensions were quantified by plating on Sabouraud dextrose agar (SDA; Difco Laboratories) plates.

\section{MIC and MFC determination of hydroxychavicol}

The MIC was performed by broth microdilution methods as per the guidelines of Clinical and Laboratory Standard Institute (formerly, the National Committee for Clinical Laboratory Standards) [16,17], with RPMI 1640 medium 


\section{A}



B

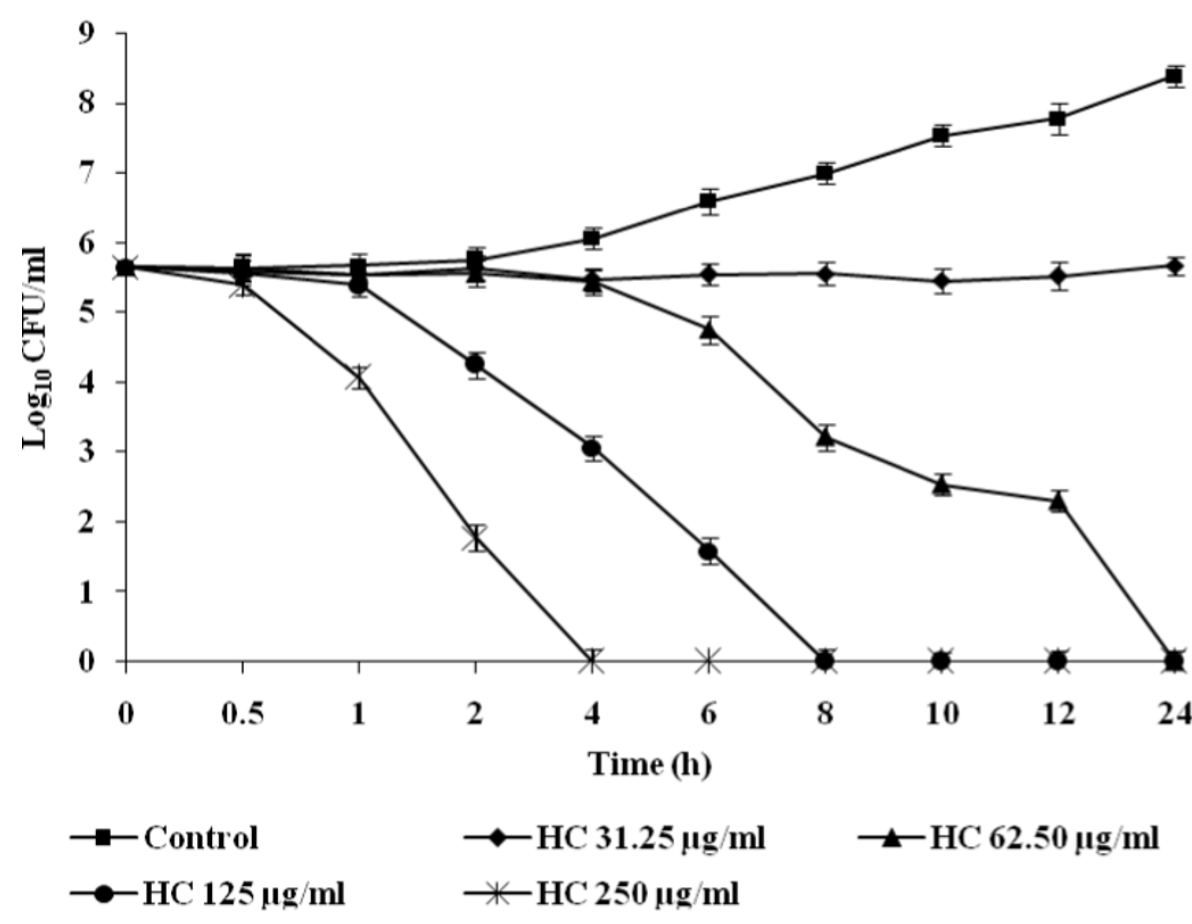

Figure 2 Time-kill curve plots for Candida species following exposure to hydroxychavicol (HC). C. albicans ATCC 90028 (A), C. glabrata ATCC 90030 (B). Each time point represents the mean $\log _{10} \pm$ standard deviations of two different experiments performed in duplicate. $P$ values $<0.001$ (Student's $t$-test). 
containing L-glutamine, without sodium bicarbonate and buffered to pH 7.0 with $0.165 \mathrm{M}$ morpholinepropanesulfonic acid (RPMI) (both from Sigma). Stock solution of hydroxychavicol was prepared in $100 \%$ dimethyl sulfoxide (DMSO; Sigma) and twofold serial dilutions were prepared in media in amounts of $100 \mu \mathrm{l}$ per well in 96-well U-bottom microtiter plates (Tarson, Mumbai, India). The above-mentioned fungal suspensions were further diluted in media, and a $100 \mu \mathrm{l}$ volume of this diluted inoculum was added to each well of the plate, resulting in a final inoculum of $0.5 \times 10^{4}$ to $2.5 \times 10^{4} \mathrm{cfu} / \mathrm{ml}$ [19] for yeasts and $0.4 \times 10^{4}$ to $5 \times 10^{4} \mathrm{cfu} / \mathrm{ml}$ for dermatophytes and Aspergillus species. The final concentration of hydroxychavicol ranged from 3.90 to $2000 \mu \mathrm{g} / \mathrm{ml}$. The medium without the agents was used as a growth control and the blank control used contained only the medium. Amphotericin $\mathrm{B}$ and terbinafine served as the standard drug controls. The microtiter plates were incubated at $28^{\circ} \mathrm{C}$ for 7 days for dermatophytes [18], and at $35^{\circ} \mathrm{C}$ for $48 \mathrm{~h}$ for Candida species (72 h for C. neoformans) and Aspergillus species $[16,17]$. The plates were read visually, and the MIC was defined as the lowest concentration of the antifungal agents that prevented visible growth with respect to the growth control.

The MFC was determined by plating a $100 \mu \mathrm{l}$ volume on SDA from the wells showing no visible growth. The plates were incubated as described above in MIC. The minimum concentration of hydroxychavicol that showed $\geq 99.9 \%$ reduction of the original inoculums was recorded as the MFC [19].

\section{Time kill curve studies}

Time-kill curve studies were performed as described by Ernst et al [20], using RPMI. C. albicans ATCC 90028 and C. glabrata ATCC 90030 were used as the test strains in this study. One milliliter of the adjusted inoculum suspension $\left(\approx 5 \times 10^{6} \mathrm{cfu} / \mathrm{ml}\right)$ was added to nine $\mathrm{ml}$ of RPMI with or without hydroxychavicol, providing the starting inoculum of $\approx 5 \times 10^{5} \mathrm{cfu} / \mathrm{ml}$. The range of hydroxychavicol concentrations tested was one to eight times the MICs for test strains i.e. 250 to $2000 \mu \mathrm{g} / \mathrm{ml}$ for C. albicans and 31.5 to $250 \mu \mathrm{g} /$ $\mathrm{ml}$ for C. glabrata. The culture flasks were incubated with agitation at $35^{\circ} \mathrm{C}$. At predetermined time points $(0,0.5,1,2,4,6,8,10,12$, and $24 \mathrm{~h}$ following the addition of hydroxychavicol), a $100 \mu$ l aliquot was removed from each culture flask and serially diluted in sterile normal saline containing $0.1 \%$ polysorbate 80 (Sigma) for the inactivation of hydroxychavicol. A 20 $\mu \mathrm{l}$ aliquot was plated onto a Sabouraud dextrose agar with lecithin and polysorbate 80 (BBL, Becton Dickinson and Company, Cockeysville, MD) plate for colony count determination. When the colony counts were expected to be less than $1000 \mathrm{cfu} / \mathrm{ml}$, samples of $20 \mu \mathrm{l}$ or $100 \mu \mathrm{l}$ were taken directly from the test solution and plated or subcultured without dilution. Plates were then incubated at $35^{\circ} \mathrm{C}$ for 24 to $48 \mathrm{~h}$. The lower limit of accurate and reproducible quantification was $50 \mathrm{cfu} /$ $\mathrm{ml}$ for each of the strains.

\section{Postantifungal effect (PAFE)}

The PAFE of hydroxychavicol was performed in RPMI by the method described by Craig and Gudmundsson [21]. C. albicans ATCC 90028, C. tropicalis ATCC 750, C. glabrata ATCC 90030 and C. parapsilosis ATCC 22019 were used as the test strains in this study. One milliliter of the adjusted inoculum suspension $(\approx 5 \times$ $10^{7} \mathrm{cfu} / \mathrm{ml}$ ) was added to nine $\mathrm{ml}$ of RPMI with or without hydroxychavicol, providing the starting inoculum of $\approx 5 \times 10^{6} \mathrm{cfu} / \mathrm{ml}$. The hydroxychavicol concentrations ranged from one to four times the MIC. After exposures to the hydroxychavicol for $2 \mathrm{~h}$, samples were diluted to 1: 1,000 in prewarmed medium to effectively remove the hydroxychavicol. The diluted cultures were then incubated with agitation (200 rpm) at $35^{\circ} \mathrm{C}$ and sampling was done after $0,2,4,6,8,10,12,16$ and $24 \mathrm{~h}$ for colony counts. The colony counts were determined as described above in time-kill curve studies. The PAFE was calculated by the following equation: PAFE $=T-C$, where $T$ represents the time required for the count in the test culture to increase $1 \log _{10} \mathrm{cfu} / \mathrm{ml}$ above the count observed immediately after drug (hydroxychavicol) removal and $C$ represents the time required for the count of the untreated control flask to increase by 1 $\log _{10} \mathrm{cfu} / \mathrm{ml}$.

\section{Selection of resistant mutants in vitro}

The first step mutant frequency of reference strains of C. albicans ATCC 90028, C. tropicalis ATCC 750, C. glabrata ATCC 90030, C. parapsilosis ATCC 22019, A. flavus MTCC 2799 and $A$. fumigatus MTCC 1811 were selected, using previously described method [22]. A fungal suspension containing $10^{9} \mathrm{cfu}(100 \mu \mathrm{l})$ was plated on SDA containing hydroxychavicol at concentrations equal to two, four and eight times the MIC. Mutation frequency was calculated by counting the total number of colonies appearing after $48 \mathrm{~h}$ of incubation at $35^{\circ} \mathrm{C}$ on the hydroxychavicol containing plate and by dividing the number by the total number of cfu plated.

\section{Minimum biofilm inhibitory concentrations (MBICs)}

The effect of hydroxychavicol on C. albicans ATCC 90028 biofilm formation was examined by the microbroth dilution method, similar to MIC assays for planktonic cells [16] as described above. The fungal suspension was prepared from the overnight culture grown in yeast nitrogen base (Difco Laboratories) medium supplemented with $100 \mathrm{mM}$ glucose [23], and the 
Table 1 MICs and MFCs of hydroxychavicol for 124 strains of selected fungi determined by the broth microdilution method

\begin{tabular}{|c|c|c|c|}
\hline \multirow[t]{2}{*}{ Species } & \multirow[t]{2}{*}{$\begin{array}{l}\text { No of strains } \\
\text { tested }\end{array}$} & \multicolumn{2}{|c|}{$\begin{array}{c}\text { Antifungal activity in } \\
\mu \mathrm{g} / \mathrm{ml}\end{array}$} \\
\hline & & $\begin{array}{c}\text { MIC } \\
\text { range }\end{array}$ & $\begin{array}{c}\text { MFC } \\
\text { range }\end{array}$ \\
\hline $\begin{array}{l}\text { C. albicans ATCC } 90028, \\
10231\end{array}$ & 2 & 250 & 250 \\
\hline C. albicans (Cl) & 23 & $125-500$ & $250-500$ \\
\hline C. glabrata ATCC 90030 & 1 & 31.25 & 31.25 \\
\hline C. glabrata $(\mathrm{Cl})$ & 7 & $\begin{array}{l}15.62- \\
31.25\end{array}$ & $\begin{array}{c}15.62- \\
62.5\end{array}$ \\
\hline C. krusei ATCC 6258 & 1 & 15.62 & 15.62 \\
\hline C. krusei(Cl) & 3 & $\begin{array}{l}15.62- \\
31.25\end{array}$ & $\begin{array}{l}15.62- \\
31.25\end{array}$ \\
\hline C. parapsilosis ATCC 22019 & 1 & 31.25 & 31.25 \\
\hline C. parapsilosis $(\mathrm{Cl})$ & 5 & $\begin{array}{l}31.25- \\
62.5\end{array}$ & $\begin{array}{c}31.25- \\
62.5\end{array}$ \\
\hline C. tropicalis ATCC 750 & 1 & 250 & 250 \\
\hline C. tropicalis $(\mathrm{Cl})$ & 11 & $125-500$ & $250-500$ \\
\hline $\begin{array}{l}\text { C. neoformans ATCC } \\
204092\end{array}$ & 1 & 62.5 & 62.5 \\
\hline C. neoformans (Cl) & 2 & 62.5 & 62.5 \\
\hline A. flavus MTCC 1973, 2799 & 2 & 250 & 250 \\
\hline A. flavus $(\mathrm{Cl})$ & 11 & $125-500$ & $125-500$ \\
\hline A. fumigatus MTCC 1811 & 1 & 250 & 250 \\
\hline A. fumigatus $(\mathrm{Cl})$ & 17 & $125-500$ & $250-500$ \\
\hline A. niger ATCC 16404 & 1 & 125 & 125 \\
\hline A. niger $(\mathrm{Cl})$ & 6 & $125-250$ & $125-250$ \\
\hline A. parasiticus MTCC 2796 & 1 & 250 & 250 \\
\hline E. floccosum MTCC 613 & 1 & 15.62 & 15.62 \\
\hline E. floccosum $(\mathrm{Cl})$ & 1 & 15.62 & 31.25 \\
\hline M. canis MTCC 2820 & 1 & 15.62 & 31.25 \\
\hline M. canis $(\mathrm{Cl})$ & 3 & $7.81-15.62$ & $\begin{array}{l}15.62- \\
31.25\end{array}$ \\
\hline M. gypsium MTCC 2819 & 1 & 15.62 & 31.25 \\
\hline M. gypsium $(\mathrm{Cl})$ & 2 & $\begin{array}{l}15.62- \\
31.25\end{array}$ & $\begin{array}{c}31.25- \\
62.5\end{array}$ \\
\hline $\begin{array}{l}\text { T. mentagrophytes ATCC } \\
9533\end{array}$ & 1 & 15.62 & 15.62 \\
\hline T. mentagrophytes $(\mathrm{Cl})$ & 7 & $\begin{array}{l}15.62- \\
31.25\end{array}$ & $\begin{array}{l}15.62- \\
62.5\end{array}$ \\
\hline T. rubrum MTCC 296 & 1 & 31.25 & 31.25 \\
\hline T. rubrum (Cl) & 9 & $\begin{array}{l}15.62- \\
62.5\end{array}$ & $\begin{array}{c}31.25- \\
62.5\end{array}$ \\
\hline
\end{tabular}

MIC and MFC of yeast was determined by using higher inoculums [19]. Cl, clinical isolate.

cells were harvested in the late exponential growth phase, washed twice with sterile phosphate-buffered saline (PBS; pH 7.2; $\mathrm{Ca}^{2+}$ and $\mathrm{Mg}^{2+}$ free [Hi Media]) and the turbidity of the suspension was adjusted to 4 McFarland standard $\left(\approx 5 \times 10^{7} \mathrm{cfu} / \mathrm{ml}\right)$. The suspension was diluted in RPMI to obtain $\approx 5 \times 10^{6} \mathrm{cfu} / \mathrm{ml}$ as the final inoculums. Twofold serial dilutions of hydroxychavicol were prepared in RPMI in the wells of a 96-well flatbottom polystyrene microtiter plate (NUNC, Roskilde, Denmark) containing the same media in a volume of $100 \mu \mathrm{l}$ per well. A $100 \mu \mathrm{l}$ of above-mentioned suspension was added to each well; the final concentrations of hydroxychavicol ranged from 1.95 to $2000 \mu \mathrm{g} / \mathrm{ml}$. Amphotericin B (at a final concentration range from 0.0156 to $16 \mu \mathrm{g} / \mathrm{ml}$ ) was used as control drug. Following incubation at $35^{\circ} \mathrm{C}$ for $48 \mathrm{~h}$, absorbance at $490 \mathrm{~nm}$ was recorded to assess culture growth. The culture supernatants from each well were then decanted, and planktonic cells were removed by washing the wells with sterile PBS. Biofilm formation was quantified by tetrazolium salt (XTT) reduction assay (see below).

\section{Minimum biofilm reduction concentrations (MBRCs)}

The effect of hydroxychavicol was also examined on preformed C. albicans ATCC 90028 biofilm by the method as described previously [24]. Biofilms were prepared by inoculating the wells of a polystyrene microtiter plate in a manner similar to that described above. After incubation at $35^{\circ} \mathrm{C}$ for $48 \mathrm{~h}$, the culture supernatant from each well was decanted, and the planktonic cells were removed by washing the wells with PBS. Two fold serial dilutions of hydroxychavicol were prepared in RPMI, and $200 \mu \mathrm{l}$ of each dilution was added to the biofilm in the wells. The plate was further incubated at $35^{\circ}$ $\mathrm{C}$ for $48 \mathrm{~h}$. The final concentrations of hydroxychavicol ranged from 1.95 to $2000 \mu \mathrm{g} / \mathrm{ml}$. Amphotericin B (at a final concentration range from 0.0156 to $16 \mu \mathrm{g} / \mathrm{ml}$ ) was used as control drug. After the completion of incubation, the plates were decanted and washed three times with $200 \mu \mathrm{l}$ of sterile PBS to remove loosely adherent cells. Biofilm reduction was quantified by XTT-reduction assay described below.

\section{$\mathrm{XTT}$-reduction assay}

XTT (tetrazolium salt 2, 3-bis (2-methoxy-4-nitro-5sulfo-phenyl)-2H-tetrazolium-5-carboxanilide) reduction assay was performed by the method as described by Jin et al., [23]. The XTT (Sigma) solution was prepared in PBS $(1 \mathrm{mg} / \mathrm{ml})$, filter-sterilized through a $0.22-\mu \mathrm{m}$-poresize filter (Millipore, Bangalore, India) and stored at $-80^{\circ}$ $\mathrm{C}$ until required. Menadione (Sigma) solution $(0.4 \mathrm{mM}$ prepared in acetone) was filtered and mixed with XTT solution at a ratio of 1 to 5 by volume before the assay. $200 \mu \mathrm{l}$ of PBS and $12 \mu \mathrm{l}$ of the XTT-Menadione solution were added to each of the washed wells and the plate was incubated in the dark for $2 \mathrm{~h}$ at $35^{\circ} \mathrm{C}$. Following incubation, $100 \mu \mathrm{l}$ of the solution was transferred to a fresh microtiter plate and, the color change in the solution was measured spectrophometrically using a microtitre plate reader (Multiskan spectrum, Thermo electron, Vantaa, Finland) at $490 \mathrm{~nm}$. 
Table 2 PAFE values of hydroxychavicol for Candida species after $\mathbf{2}$ h of exposure

\begin{tabular}{|c|c|c|c|}
\hline \multirow[t]{2}{*}{ Species } & \multicolumn{3}{|c|}{ PAFEs $(h)$ (mean \pm SD) at the following multiple of the MIC: } \\
\hline & $1 \times \mathrm{MIC}$ & $2 \times \mathrm{MIC}$ & $4 \times \mathrm{MIC}$ \\
\hline C. albicans ATCC 90028 & $5.53 \pm 0.3$ & $6.34 \pm 0.2$ & $8.64 \pm 0.3$ \\
\hline C. tropicalis ATCC 750 & $4.4 \pm 0.6$ & $6.4 \pm 0.4$ & $8.70 \pm 0.2$ \\
\hline C. glabrata ATCC 90030 & $3.08 \pm 0.4$ & $3.76 \pm 0.6$ & $8.04 \pm 0.1$ \\
\hline C. parapsilosis ATCC 22019 & $2.0 \pm 0.1$ & $4.0 \pm 0.2$ & $6.25 \pm 0.3$ \\
\hline
\end{tabular}

\section{Propidium iodide uptake assay}

The disruptive effect of hydroxychavicol on Candida albicans ATCC 90028 cell membranes was assessed by using hydroxychavicol-mediated propidium iodide uptake. One-milliliter volumes of $\approx 5 \times 10^{7} \mathrm{cfu} / \mathrm{ml}$ cell suspensions of $C$. albicans in sterile MilliQ water were incubated with two to eight times the MIC (500 to 2000 $\mu \mathrm{g} / \mathrm{ml}$ ) of hydroxychavicol at $35^{\circ} \mathrm{C}$ for 60 min under agitation in the dark chamber. Fifteen minutes prior to the completion of incubation, $10 \mu \mathrm{l}$ each of propidium iodide and sodium deoxycholate solution were added at a final concentration of $25 \mu \mathrm{g} / \mathrm{ml}$ and $2.5 \mathrm{mg} / \mathrm{ml}$ "respectively" [14,15]. Amphotericin B at eight times the MIC $(4.0 \mu \mathrm{g} / \mathrm{ml})$ was used as the positive control and, the cells without hydroxychavicol served as the negative (growth) control, treated in similar fashion. After incubation, $50 \mu \mathrm{l}$ aliquot was transferred into fluorescenceactivated cell sorting (FACS) tube (Becton Dickinson Biosciences, CA) containing $950 \mu \mathrm{l}$ of sterile MilliQ water. Each tube was analyzed using a FACScan flow cytometer (BD-LSR; Becton Dickinson) with Cell Quest Pro software for data acquisition and analysis.

\section{Results}

Antifungal susceptibility results

The MICs and MFCs of hydroxychavicol were evaluated in vitroagainst 58 strains of yeasts, 39 strains of Aspergillus species and 27 strains of dermatophytes and all values are listed in Table 1. Hydroxychavicol exhibited the MICs range between 15.62 to $500 \mu \mathrm{g} / \mathrm{ml}$ for yeasts, 125 to $500 \mu \mathrm{g} / \mathrm{ml}$ for Aspergillus species and 7.81 to

Table 3 Frequency of mutation with hydroxychavicol

\begin{tabular}{lccc}
\hline Tested strains & \multicolumn{3}{c}{$\begin{array}{c}\text { Mutation frequency with } \\
\text { hydroxychavicol at: }\end{array}$} \\
\cline { 2 - 4 } & $\mathbf{2} \times \mathbf{M I C}$ & $\mathbf{4} \times$ MIC & $\mathbf{8} \times \mathbf{M I C}$ \\
\hline C. albicans ATCC 90028 & $2.5 \times 10^{9}$ & $<10^{9}$ & $<10^{9}$ \\
C. tropicalis ATCC 750 & $2 \times 10^{9}$ & $<10^{9}$ & $<10^{9}$ \\
C. glabrata ATCC 90030 & $1.5 \times 10^{9}$ & $1.5 \times 10^{9}$ & $<10^{9}$ \\
C. parapsilosis ATCC 22019 & $2 \times 10^{9}$ & $2 \times 10^{9}$ & $<10^{9}$ \\
A. fumigatus MTCC 1811 & $<10^{9}$ & $<10^{9}$ & $<10^{9}$ \\
A. flavus MTCC 1973 & $<10^{9}$ & $<10^{9}$ & $<10^{9}$ \\
\hline
\end{tabular}

MIC of hydroxychavicol is $31.25 \mu \mathrm{g} / \mathrm{ml}$ for C. glabrata and C. parapsilosis while as $250 \mu \mathrm{g} / \mathrm{ml}$ for other species tested.
$62.5 \mu \mathrm{g} / \mathrm{ml}$ for dermatophytes, where as the MFCs were found to be similar or two fold greater than the MICs. Among all the fungal species tested, dermatophytes were found to be the most susceptible species to hydroxychavicol.

\section{Time kill curve studies}

The killing activities of hydroxychavicol for C. albicans ATCC 90028 and C. glabrata ATCC 90030 are shown

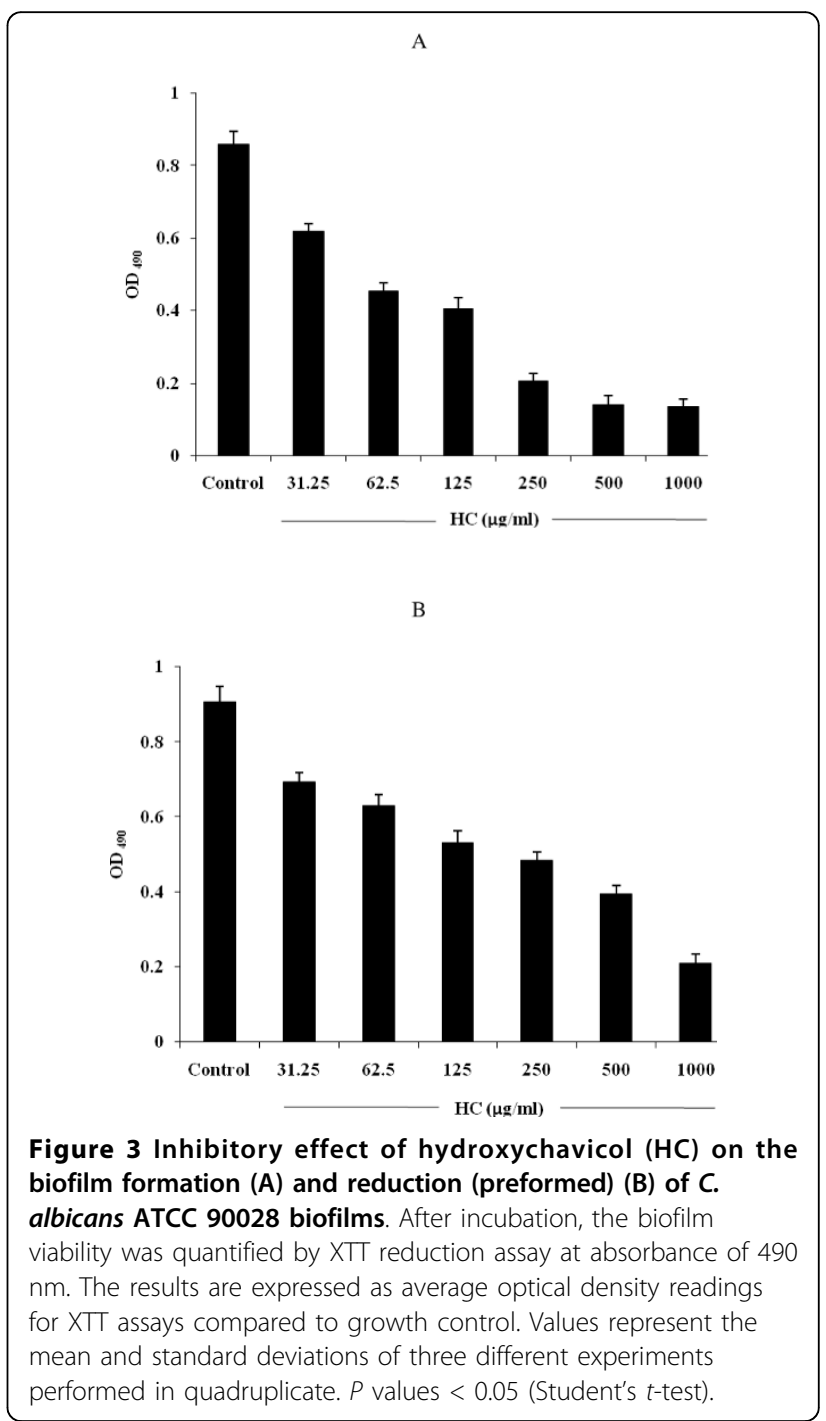




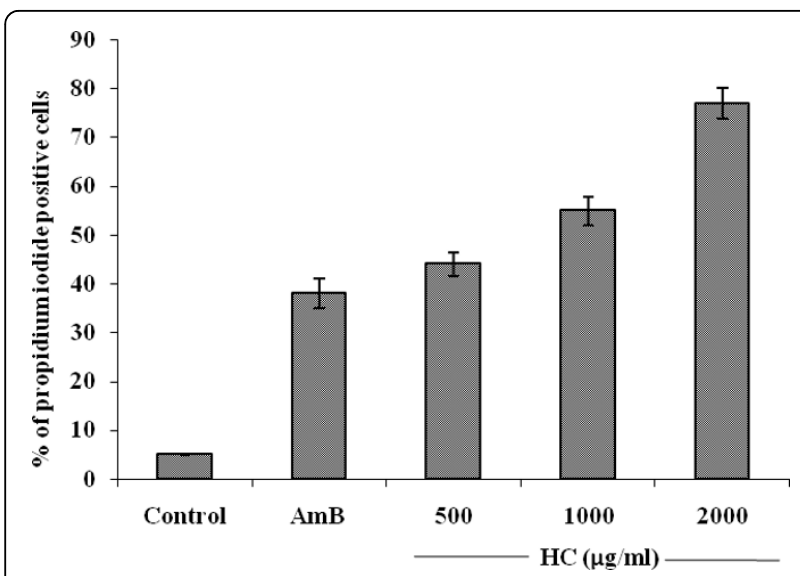

Figure 4 Uptake of propidium iodide in cell suspension of $C$. albicans ATCC 90028. Cells $\left(\approx 5 \times 10^{7} \mathrm{cfu} / \mathrm{ml}\right)$ were exposed to two to eight times (500 to $2000 \mu \mathrm{g} / \mathrm{ml}$ ) the MIC of hydroxychavicol (HC) for $60 \mathrm{~min}$. Amphotericin B at eight times the MIC $(4.0 \mu \mathrm{g} / \mathrm{ml})$ was used as the positive control and, the cells without hydroxychavicol served as the growth control. Data represent the mean and standard deviations of two different experiments performed in triplicate. $P$ values $<0.05$ (Student's $t$-test).

in Fig. 2. Hydroxychavicol exhibited fungicidal activity against both Candida species and the reduction in the number of cfu per milliliter was greater than $3 \log$ units (99.9\%). The fungicidal endpoint for C. albicans was achieved after 10 and $1 \mathrm{~h}$ at $4 \times \mathrm{MIC}(4 \times 250 \mu \mathrm{g} / \mathrm{ml})$ and $8 \times \mathrm{MIC}(8 \times 250 \mu \mathrm{g} / \mathrm{ml})$ of hydroxychavicol (Fig. 2A). In C. glabrata, killing was observed at a lower concentration of hydroxychavicol due to its lower MIC. There was concentration dependent killing observed in case of C. glabrata, with two, four and eight times the MIC exhibited fungicidal activity in 10, 8 and $4 \mathrm{~h}$ "respectively".

\section{PAFE studies}

Hydroxychavicol produced significant PAFE against all the Candida species tested (Table 2). Increase in the concentration of hydroxychavicol resulted in extended PAFE for all the Candida spp. tested. This increase in PAFE was more prominent for C. albicans and C. tropicalis, where a PAFE of $>8 \mathrm{~h}$ was exhibited in these organisms at four times the MIC concentration of hydroxychavicol.

\section{Frequency of emergence of hydroxychavicol resistant mutants}

The frequencies of mutant selection of C. albicans, $C$. tropicalis, C. glabrata, C. parapsilosis, A. fumigatus, and A. flavus, are summarized in Table 3. Hydroxychavicol completely suppressed the emergence of mutants at two times its MIC for A. fumigatus and A. flavus, four times the MIC for C. albicans and C. tropicalis, and eight times the MIC for C. glabrata and C. parapsilosis "respectively". This concentration of hydroxychavicol at which no mutant was selected can be defined as the mutation prevention concentration.

\section{Biofilm susceptibility assay}

Hydroxychavicol exhibited an inhibitory effect on the biofilm formation and reduction of preformed biofilm of C. albicans ATCC 90028 . The $50 \%$ and $80 \%$ biofilm inhibition as well as biofilm reduction are represented in Fig. 3. The $\mathrm{MBIC}_{50}$ and $\mathrm{MBIC}_{80}$ values of hydroxychavicol were $125 \mu \mathrm{g} / \mathrm{ml}$ and $250 \mu \mathrm{g} / \mathrm{ml}$, where as the $\mathrm{MBRC}_{50}$ and $\mathrm{MBRC}_{80}$ values were $500 \mu \mathrm{g} / \mathrm{ml}$ and 1000 $\mu \mathrm{g} / \mathrm{ml}$. Reductions of preformed biofilms values were four fold greater than the concentration required to inhibit biofilm formation.

\section{Effect of hydroxychavicol on membrane permeability}

Exposing the cell suspension of $C$. albicans ATCC 90028 to two to eight times (500 to $2000 \mu \mathrm{g} / \mathrm{ml}$ ) the MIC of hydroxychavicol for $60 \mathrm{~min}$ increased the cell permeability to the fluorescent nucleic acid stain, propidium iodide due to the disruption of membrane integrity. This resulted in the increase in fluorescence in comparison to untreated control (Fig. 4). This increase in fluorescence was proportional to the increase in the hydroxychavicol concentrations.

\section{Discussion}

In this study, we evaluated the antifungal activities of hydroxychavicol against various fungal species. Hydroxychavicol demonstrated fungicidal effects against all the fungal species tested including Candida spp., Aspergillus spp. and dermatophytes. The fungicidal effect was most pronounced in dermatophytes including T. rubrum (MICs and MFCs were $15.62-62.5 \mu \mathrm{g} / \mathrm{ml}$ ) which is the etiological agent of 80 to $93 \%$ of all clinical infections produced by dermatophytes [3]. Hydroxychavicol also exhibited concentration dependent killing and extended PAFE of $>8 \mathrm{~h}$. In the concentration range of 250-1000 $\mu \mathrm{g} / \mathrm{ml}$ it completely suppressed the emergence of mutants of various Candida and Aspergillus species tested.

C. albicans is most commonly associated with biofilm formation, and the increase in Candida infections in the last decades has almost paralleled the increase and widespread use of a broad range of medical implant devices (such as stents, prostheses, implants, endotracheal tubes, pacemakers, and catheters), mainly in populations with impaired host defenses. Biofilm formation on medical devices can negatively impact the host by causing the failure of the device and by serving as a reservoir or source for future continuing infections [25]. Hydroxychavicol was effective in inhibiting the $C$. albicans 
generated biofilm with $80 \%$ inhibition of biofilm was observed at the MIC concentration $(250 \mu \mathrm{g} / \mathrm{ml})$. However the reduction of the preformed biofilm was seen at four fold greater concentrations.

There have been reports on the antifungal activities of $P$. betle. Pongpech and Prasertsilpe [26] found that $P$. betle gel inhibited growth of dermatophytes that cause ringworm and growth of Candida species more effectively than tolnaftate and with a similar inhibitory effect to that of clotrimazole. Recently, Trakranrungsie et al [27] also reported the antidermatophytic activity of $P$. betle extract against M. canis, M. gypseum and T. mentagrophyte by broth dilution method and showed that $P$. betle exhibited more effective antifungal properties with average $\mathrm{IC}_{50}$ and $\mathrm{IC}_{90}$ values ranging from 110.44 to $119.00 \mu \mathrm{g} / \mathrm{ml}$ and 230.40 to $492.30 \mu \mathrm{g} / \mathrm{ml}$ "respectively".

Hydroxychavicol is one of the major constituents of $P$. betle. It has been extensively reported for its antibacterial activity $[12,13]$. However its antifungal activity has not been reported so far. Here in this study we have for the first time reported the antifungal potential of hydroxychavicol.

Propidium iodide is a fluorescent nucleic acid stain that is unable to penetrate the cell membrane structures of healthy cells. However, cells with damaged or permeabilised cell membranes do not exclude propidium iodide. Therefore, propidium iodide staining of cells indicates cytoplasmic membrane (bacteria) and plasma membrane (yeast) damage [28]. Sodium deoxycholate was used in this study as it is reported to enhance the diffusion of propidium iodide across the cell wall to pass through the damaged yeast cell membranes $[29,15]$. Interestingly, the growth controls did not show dye uptake in the presence of deoxycholate as the deoxycholate is nontoxic to $C$. albicans [29]. The increased uptake of propidium iodide in the hydroxychavicol treated cells of C. albicans in our study, further confirmed the earlier findings that hydroxychavicol alters the cell membrane structure, resulting in the disruption of the permeability barrier of microbial membrane structures [30].

The clinical applications of hydroxychavicol were challenging to interpret in this study due to a lack of pharmacokinetic and safety studies. However its comparable cytotoxicity profile with that of thymol widely used natural phenolic as food preservative and oral care agent in the earlier study [12] is indicative of the safety of this compound.

\section{Conclusions}

The results presented in this study are the first information of hydroxychavicol for antifungal activity. Hydroxychavicol exhibited a broad range antifungal activity against clinically significant human fungal species. Further studies are therefore warranted in order to explore of this natural compound for topical use in fungal infections particularly dermatomycoses.

\section{Abbreviations}

MIC: minimum inhibitory concentration; MFC: minimum fungicidal concentration; ATCC: american type culture collection; MTCC: microbial type culture collection; cfu: colony forming unit; MOPS:

morpholinepropanesulfonic acid; DMSO: dimethyl sulfoxide; PAFE: postantifungal effect; MBIC: minimum biofilm inhibitory concentration; MBRC: minimum biofilm reduction concentration; XTT: 2, 3-bis (2-methoxy-4nitro-5-sulfo-phenyl)-2H-tetrazolium-5-carboxanilide.

\section{Acknowledgements}

We are thankful to Lupin Pharmaceuticals (Pune, India) for providing terbinafine. Research fellowship was provided to Mr. Intzar Ali by Council of Scientific and Industrial Research (CSIR), New Delhi, India (P-81101).

\section{Author details}

${ }^{1}$ Clinical Microbiology Division Indian Institute of Integrative Medicine, Canal Road, Jammu-180 001, India. ${ }^{2}$ Natural Product Chemistry Division, Indian Institute of Integrative Medicine, Canal Road, Jammu-180 001, India.

${ }^{3}$ Department of Microbiology, Acharya Shri Chander College of Medical Sciences, Sidhra, Jammu-180 017, India. ${ }^{4}$ Department of Biotechnology, Faculty of Science, Hamdard University, Hamdard Nagar, New Delhi-110 062, India.

\section{Authors' contributions}

IA was carried out all experimental work, data acquisition and analysis, literature search and writing the manuscript. IAK and FA were responsible for study concept, designing and coordinating the research, supervising the work and revising the manuscript. FGK is the collaborator from the Medical College and provided the clinical inputs in the manuscript. KAS, BDG, NKS and PD involved in extraction and characterization of hydroxychavicol from Piper betle. GNQ was involved in critical evaluation of the manuscript. All authors have read and approved the final manuscript.

\section{Competing interests}

The authors declare that they have no competing interests.

Received: 7 August 2009

Accepted: 3 February 2010 Published: 3 February 2010

\section{References}

1. Fontenelle ROS, Morais SM, Brito EHS, Kerntopf MR, Brilhante RSN, Cordeiro RA, Tome AR, Queiroz MGR, Nascimento NRF, Sidrim JJC, Rocha MFG: Chemical composition, toxicological aspects and antifungal activity of essential oil from Lippia sidoides Cham. J Antimicrob Chemother 2007, 59:934-940.

2. White TC, Marr KA, Bowden RA: Clinical, cellular and molecular factors that contribute to antifungal drug resistance. Clin Microbiol Rev 1998, 11:382-402.

3. Muschietti L, Derita M, Sulsen V, de Dios Munoz J, Ferraro G, Zacchino S, Martino V: In vitro antifungal assay of traditional Argentine medicinal plants. J Ethnopharmacol 2005, 102:233-238.

4. Nakamura CV, Ishida K, Faccin LC, Filho BPD, Cortez DAG, Rozental S, de Souza W, Ueda-Nakamura T: In vitro activity of essential oil from Ocimum gratissimum L. against four Candida species. Research in Microbiol 2004, 155:579-586.

5. Singh M, Shakya S, Soni VK, Dangi A, Kumar N, Bhattacharya SM: The nhexane and chloroform fractions of Piper betle L., trigger different arms of immune responses in BALB/c mice and exhibit antifilarial activity against human lymphatic filarid Brugia malayi. Int Immunopharmacol 2009, 9:716-728.

6. Anonymous: The Wealth of India. The Dictionary of Indian Raw Materials and Industrial Products. Raw Material, revised edition Publication and Information directorate, CSIR, New Delhi 1992, 5:84-94.

7. Norton SA: Betel: consumption and consequences. J Am Acad Dermatol 1998, 38:81-88. 
8. Prabhu MS, Patel K, Saraawathi G, Srinivasan K: Effect of orally administered betel leaf (Piper betle leaf Linn.) on digestive enzymes of pancreas and intestinal mucosa and on bile production in rats. Indian $J$ Expt Biol 1995, 33:752-756.

9. Bhattacharya S, Banergee D, Bauri AK, Chattopadhyay S, Bandyopadhyay SK: Healing properties of the Piper betle phenol, allylpyrocatechol against indomethacin-induced stomach ulceration and mechanism of action. World J Gastroenterol 2007, 21:3705-3713.

10. Chang MC, Uang BJ, Wu HL, Lee JJ, Hahn LJ, Jeng JH: Inducing the cell cycle arrest and apoptosis of oral KB carcinoma cells by hydroxychavicol: Roles of glutathione and reactive oxygen species. $\mathrm{Br} \mathrm{J}$ Pharmacol 2002, 135:619-630.

11. Chang MC, Uang BJ, Tsai CY, Wu HL, Lin BR, Lee CS, Chen YJ, Chang CH, Tsai YL, Kao CJ, Jeng JH: Hydroxychavicol, a novel betel leaf component, inhibits platelet aggregation by suppression of cyclooxygenase, thromboxane production and calcium mobilization. Br J Pharmacol 2007, 152:73-82.

12. Sharma S, Khan IA, Ali I, Ali F, Kumar M, Kumar A, Johri RK, Abdullah ST, Bani S, Pandey A, Suri KA, Gupta BD, Satti NK, Dutt P, Qazi GN: Evaluation of the antimicrobial, antioxidant and anti-inflammatory activities of hydroxychavicol for its potential use as an oral care agent. Antimicrob Agents Chemother 2009, 53:216-222.

13. Ramji N, Ramji N, lyer R, Chandrasekaran S: Phenolic antibacterials from Piper betle in the prevention of halitosis. J Ethnopharmacol 2002, 83:149-52.

14. Green L, Petersen B, Steimel L, Haeber P, Current W: Rapid determination of antifungal activity by flow cytometry. J Clin Microbiol 1994, 32:1088-1091

15. Joung YH, Kim HR, Lee MK, Park AJ: Fluconazole susceptibility testing of Candida species by flow cytometry. J Infect 2007, 54:504-508.

16. Clinical and Laboratory Standards Institute (CLSI): Reference method for broth dilution antifungal susceptibility testing of yeasts, as the document is M27-A2., Wayne, PA. USA..

17. Clinical and Laboratory Standards Institute (CLSI): Reference method for broth dilution antifungal susceptibility testing of filamentous fungi, as the document is M38-A., Wayne, PA. USA.

18. Barros MES, Santos DA, Hamdan JS: In vitro methods for antifungal susceptibility testing of Trichophyton spp. Mycol Res 2006, 110:1355-1360.

19. Canton E, Peman J, Viudes A, Quindos G, Gobernado M, Espinel-Ingroff A: Minimum fungicidal concentrations of amphotericin $B$ for bloodstream Candida species. Diagn Microbiol Infect Dis 2003, 45:203-206.

20. Ernst EJ, Roling EE, Petzold CR, Keele DJ, Klepser ME: In vitro activity of micafungin (FK-463) against Candida spp.: microdilution, time-Kill, and postantifungal-effect studies. Antimicrob Agents Chemother 2002, 46:3846-3853.

21. Craig WA, Gudmundsson S: Postantibiotic effect. Antibiotics in laboratory medicine The Williams and Wilkins Co., Baltimore, MD. USAVictor Lorian , 4 1996, 296-329.

22. Drugeon $H B$, Juvin $M E$, Bryskier $A$ : Relative potential for selection of fluoroquinolone-resistant Streptococcus pneumoniae strains by levofloxacin: comparison with ciprofloxacin, sparfloxacin and ofloxacin. $J$ Antimicrob Chemother 1999, 43(Suppl C):55-59.

23. Jin Y, Yip HK, Samaranayake YH, Yau JY, Samaranayake LP: Biofilm-forming ability of Candida albicans is unlikely to contribute to high levels of oral yeast carriage in cases of human immunodeficiency virus infection. $J$ Clin Microbiol 2003, 41:2961-2967.

24. Ramage G, Walle KV, Wickes BL, Lopez-Ribot JL: Standardized method for in vitro antifungal susceptibility testing of Candida albicans biofilms. Antimicrob Agents Chemother 2001, 45:2475-2479.

25. Ramage G, Saville SP, Thomas DP, Lopez-Ribot JL: Candida biofilms: an update. Euk Cell 2005, 4:633-638.

26. Pongpech $P$, Prasertsilpe V: The study of antimicrobial activity of Piper betle cream and gel against some fungi, yeast and bacteria. J GPO 1993, 19:8-22.

27. Trakranrungsie N, Chatchawanchonteera A, Khunkitti W: Ethnoveterinary study for antidermatophytic activity of Piper betle, Alpinia galanga and Allium ascalonicum extracts in vitro. Research in Vet Sci 2008, 84:80-84.

28. Cox SD, Mann CM, Markham JL, Gustafson JE, Warmington JR, Wyllie SG: Determining the antimicrobial actions of tea tree oil. Molecules 2001, 6:87-91.
29. Ramani R, Ramani A, Wong SJ: Rapid flow cytometric susceptibility testing of Candida albicans. J Clin Microbiol 1997, 35:2320-2324.

30. Nalina T, Rahim ZHA: The crude aqueous extract of Piper betle L. and its antibacterial effect towards Streptococcus mutans. Am J Biotechnol Biochem 2007, 3:10-15.

\section{doi:10.1186/1476-0711-9-7}

Cite this article as: Ali et al:: In vitro antifungal activity of hydroxychavicol isolated from Piper betle L. Annals of Clinical Microbiology and Antimicrobials 2010 9:7.

\section{Submit your next manuscript to BioMed Central and take full advantage of:}

- Convenient online submission

- Thorough peer review

- No space constraints or color figure charges

- Immediate publication on acceptance

- Inclusion in PubMed, CAS, Scopus and Google Scholar

- Research which is freely available for redistribution

Submit your manuscript at www.biomedcentral.com/submit
Ciomed Central 